\title{
Influência do 24-epibrassinolídeo na tolerância ao estresse salino em plântulas de arroz
}

\section{Influence of the24-epibrassinolide on tolerance to salt stress in rice seedlings}

\author{
Cristina Ferreira Larré ${ }^{1 *}$; Patrícia Marini ${ }^{1}$; Caroline Leivas Moraes ${ }^{1}$; \\ Luciano do Amarante²; Dario Munt de Moraes $^{2}$
}

\begin{abstract}
Resumo
A salinidade pode ser considerada fator limitante ao crescimento e desenvolvimento das plantas por afetar vários processos fisiológicos. O objetivo foi determinar o efeito do 24-epibrassinolídeo na emergência, crescimento de plântulas, área foliar e concentração de clorofila em duas cultivares de arroz cultivadas em condição de estresse salino. $\mathrm{O}$ trabalho foi desenvolvido no Laboratório de Pesquisa em Sementes e na casa-de-vegetação do Departamento de Botânica da UFPel. As sementes de arroz das cvs. BRS Bojurú, tolerante a salinidade, e BRS Querência, não tolerante, foram embebidas, por duas horas, em água, $\mathrm{NaCl} 100 \mathrm{mM}$ e soluções de $\mathrm{NaCl} 100 \mathrm{mM}$ suplementadas com 24-epibrassinolídeo nas concentrações de 0,$01 ; 0,1$ e 1,0 $\mu \mathrm{M}$ e semeadas em bandeja de polipropileno expandido. O delineamento experimental utilizado foi inteiramente casualizado, com cinco tratamentos para cada cultivar, com quatro repetições. As médias foram comparadas pelo teste de Tukey $(\mathrm{p} \leqslant 5 \%)$. Na cv. BRS Querência a aplicação do 24-epibrassinolídeo incrementou a concentração de clorofila, área foliar, o comprimento das plântulas e massa seca da parte aérea, reduzindo os efeitos causados pela salinidade. No entanto, na cv. BRS Bojurú, tolerante a salinidade, a aplicação do 24-epibrassinolídeo $0,01 \mu \mathrm{M}$ não afetou as características de crescimento, porém as concentrações de 0,1 e 1,0 $\mu \mathrm{M}$ reduziram as mesmas, mas não afetaram a concentração de clorofila. O 24-epibrassinolídeo, na cv. BRS Querência, induz aumento em todas as características de crescimento, minimizando os efeitos deletérios da salinidade na cultivar sensível. Na cv. BRS Bojurú, as maiores concentrações reduzem as características de crescimento, não alterando a concentração de clorofila total.
\end{abstract}

Palavras-chave: Emergência, salinidade, brassinosteróides, Oryza sativa L.

\begin{abstract}
Salinity can be considered a limiting factor to the growth and development of plants to affect various physiological processes. The aim of this study was to determine the effect of 24 - epibrassinolide in emergence, seedling growth, leaf area and chlorophyll concentration in two cultivars of rice in salt stress condition. The study was conducted at the research laboratory of seeds and greenhouse of the Department of Botany UFPel. Rice seeds of cvs. BRS Bojurú tolerant to salinity and BRS Querência not tolerant, were soaked for two hours in water, $100 \mathrm{mMNaCl}$ and $100 \mathrm{mMNaCl}$ solutions supplemented with 24 - epibrassinolide at concentrations of $0.01,0,1$ and $1.0 \mathrm{mM}$ and sown in expanded polypropylene tray. The experimental design was completely randomized with five treatments, two cultivars and four replications. Means were compared by Tukey test $(\mathrm{p}<5 \%)$, within each cultivar. In cv. BRS Querência
\end{abstract}

\footnotetext{
${ }^{1}$ Dras $^{\text {as }}$ do PPG em Fisiologia Vegetal, Dept ${ }^{\circ}$ de Botânica, Universidade Federal de Pelotas, UFPel, Pelotas, RS. E-mail: cristina_ larre@yahoo.com.br; patimarini@gmail.com; caroline.moraes@gmail.com

${ }^{2}$ Profs. Associados da PPG Fisiologia Vegetal, Dept ${ }^{\circ}$ de Botânica, UFPel, Pelotas, RS. E-mail: lucianodoamarante@yahoo.com.br; moraesdm@ufpel.edu.br

* Autor para correspondência
} 
the application of 24 - epibrassinolide increased chlorophyll concentration, leaf area, seedling length and dry mass of shoots, reducing the effects caused by salinity. However, cv. BRS Bojurú, tolerant to salinity, the application of the 24 - epibrassinolide $0.01 \mathrm{mM}$ did not affect the growth characteristics, but the concentrations of 0.1 and $1.0 \mathrm{mM}$ reduced the same, no affecting the concentration of chlorophyll. The 24 - epibrassinolide in cv. BRS Querencia, induces an increase in all growth characteristics, minimizing the deleterious effects of salinity on the sensitive cultivar. In cv. BRS Bojurú, higher concentrations reduce the growth characteristics, not by changing the concentration of chlorophyll.

Key words: Emergence, salinity, brassinosteroids, Oryza sativa L.

\section{Introdução}

O arroz é um dos cereais mais cultivados no mundo, sendo amplamente utilizado na alimentação humana, desempenhando papel importante tanto no aspecto econômico quanto social. Além de ser uma cultura extremamente versátil, que se adapta a diferentes condições de solo e clima, é considerada a espécie que apresenta maior potencial para o combate a fome no mundo (AGRIANUAL, 2012).

A orizicultura é muito dependente da qualidade da água de irrigação, a qual está diretamente associada à salinidade e a toxicidade. Os efeitos indiretos da salinidade ocorrem devido à concentração elevada de sódio ou outros cátions na solução do solo, que interferem nas condições físicas deste ou na disponibilidade de outros elementos, afetando indiretamente o crescimento e o desenvolvimento das plantas. Em muitos casos a concentração de sais não atinge níveis osmóticos ou tóxicos capazes de prejudicar a absorção de água pelas plantas. No entanto, a concentração de íons diversos pode provocar interferências indiretas e ser um obstáculo à absorção de nutrientes e, consequentemente, às atividades metabólicas em geral (ALSHAMMARY; QIAN; WALLNER, 2004; MANSOUR; SALAMA, 2004).

A salinidade pode ser considerada fator limitante ao crescimento e desenvolvimento das plantas por afetar vários processos fisiológicos, dentre os quais a fotossíntese, reduzindo assim a produção e alocação de biomassa. Isto ocorre porque o estresse salino, mais propriamente associado ao acúmulo de $\mathrm{NaCl}$ nos tecidos, promove redução nos processos de síntese de ATP acoplada à fase fotoquímica da fotossíntese, além de promover alterações no processo respiratório, assimilação do nitrogênio e metabolismo de proteínas (MUNNS, 2002). Em couve flor, por exemplo, as reduções nas taxas fotossintéticas parecem estar associadas a reduções no teor de clorofilas totais além de promover prejuízos diretos à integridade dos plastídios (SANTOS; AZEVEDO; CALDEIRA, 2001). O mesmo autor ainda afirma que a enzima clorofilase é estimulada a sintetizar clorofila nos primeiros dias de exposição ao estresse (estresse moderado), entretanto, tal atividade é fortemente inibida por alta concentração salina.

Hormônio vegetal é um composto orgânico sintetizado em uma parte da planta e translocado para outra parte, que em concentrações muito baixas, causa resposta fisiológica. Vários hormônios estão envolvidos na modulação da resposta das plantas ao stress, incluindo etileno, ácido abscísico, ácido salicílico e brassinosteróides (SHARMA et al., 2007). Brassinosteroides são uma nova classe de fitohormônios com estrutura esteroídica polioxigenada, dotados de pronunciada atividade reguladora do crescimento (ZULLO; ADAM, 2002). Estes reguladores de crescimento estão associados a vários processos fisiológicos dentre eles a melhora da resposta ao estresse devido ao fato de estarem envolvidos na ativação dos mecanismos de proteção contra estresses oxidativos e na alteração estrutural e permeabilidade das membranas celulares (ANURADHA; RAO, 2007).

A atividade dos brassinosteróides está associada ao aumento na tolerância aos estresses biótico e abiótico. Dentre os estresses abióticos, eles são eficientes em incrementar a resistência a altas e 
baixas temperaturas, seca, salinidade e toxicidade por metais pesados. Em arroz, o 24-epibrassinolídeo incrementa a resistência à temperaturas entre $1-5^{\circ} \mathrm{C}$ e a tolerância é associada com incremento na produção de ATP, aumento nos níveis de prolina e aumento na atividade enzimática, indicando que esse regulador de crescimento está envolvido na estabilidade de membranas e osmorregulação (RAO et al., 2002). Também foi verificada a sua capacidade em reverter o efeito inibitório causado pela salinidade, na germinação de sementes de Eucalyptus camaldulensis Dehn. (SASSE, 2003).

Diante do exposto, o objetivo foi determinar o efeito do 24-epibrassinolídeo na emergência, crescimento de plântulas, área foliar e concentração de clorofila em duas cultivares de arroz cultivadas em condição de estresse salino.

\section{Material e Métodos}

O trabalho foi conduzido no Laboratório de Fisiologia de Sementes e em Casa de Vegetação, do Departamento de Botânica, da Universidade Federal de Pelotas, utilizando sementes de arroz das cultivares BRS Bojurú, tolerante a salinidade e BRS Querência, não tolerante, procedentes da EmbrapaClima Temperado.

O experimento foi constituído por cinco tratamentos, sendo um com água destilada (controle), um com solução de $\mathrm{NaCl} 100$ mM, e três com solução salina a $100 \mathrm{mM}$ suplementada com 24-epibrassinolídeo (24-EBR) nas concentrações 0,01 (EBR1); 0,1 (EBR2); e 1,0 $\mu \mathrm{M}$ (EBR3).

As sementes das duas cultivares foram embebidas por duas horas nas respectivas soluções. Como substrato foi utilizado areia lavada colocada em bandejas de isopor multicelulares e a semeadura realizada manualmente à profundidade de 30 milímetros. Foram avaliados os seguintes testes: emergência de plântulas em casa de vegetação (E) A contagem das plântulas emersas foi realizada aos 21 dias após a semeadura (DAS) conforme as Regras para Análises de Sementes (BRASIL, 2009) e os resultados expressos em porcentagem de plântulas emergidas; índice de velocidade de emergência de plântulas em casa de vegetação (IVE) - determinado conjuntamente ao teste de emergência de plântulas, conforme descrito por Vieira e Carvalho (1994), sendo efetuada a contagem do número de plântulas emergidas diariamente, até a estabilização do estande. O IVE foi calculado segundo a fórmula proposta por Maguirre (1962), computando o número de plântulas emergidas ao dia; comprimento da parte aérea e do sistema radicular das plântulas (CPA e CR) - ao final do teste de emergência, vinte plântulas por tratamento, de cada repetição, foram utilizadas para medição com régua graduada e os resultados expressos em mm plântula ${ }^{-1}$; massa seca da parte aérea e das raízes (MSPA e MSR) - o material vegetal foi levado à estufa a $70 \pm 2{ }^{\circ} \mathrm{C}$ até atingir massa constante. A massa seca das plântulas foi determinada em balança analítica e os resultados expressos em mg plântula ${ }^{-1}$; área foliar (AF) - foi determinada utilizando o medidor de área foliar da marca Licor, modelo LI-3000 e os resultados foram expressos em $\mathrm{mm}^{2}$ plântula ${ }^{-1}$; concentração de clorofila total (CChlt) - foi determinada de acordo com a metodologia descrita por Arnon (1949) ao final do experimento e calculado segundo Lichtenthaler (1987), sendo os resultados expressos em $\mathrm{mg}$ de pigmento $\mathrm{g}^{-1} \mathrm{MF}$.

Cada tratamento foi constituído por quatro repetições, sendo que cada uma foi composta por 200 sementes. O delineamento experimental utilizado foi inteiramente casualizado. As médias dos tratamentos, em cada cultivar estudada, foram comparadas pelo teste de Tukey a 5\% de probabilidade.

\section{Resultados e Discussão}

A salinidade reduziu tanto a emergência (E) quanto o índice de velocidade de emergência (IVE) das plântulas de arroz da cultivar sensível ao sal, BRS Querência, e somente o IVE da cultivar 
tolerante, BRS Bojurú (Tabela 1). No entanto, na cv. BRS Querência o efeito do estresse salino na emergência e velocidade do processo foi revertido pela aplicação e incremento na dose de 24-epibrassinolídeo. A emergência das plântulas de arroz cv. BRS Bojurú por sua vez, foi afetada negativamente pela combinação de sal e regulador de crescimento na maior concentração utilizada $(1,0 \mu \mathrm{M})$. Além disso, o efeito da salinidade sobre o IVE nessa cultivar não foi revertido pelo 24-epibrassinolídeo (Tabela 1). Estes resultados inferem que a suplementação da solução salina com 24-epibrassinolídeo pôde proporcionar resultados eficientes em melhorar a tolerância ao estresse salino durante na fase de emergência de plântulas da cultivar BRS-Querência, não apresentando efeito positivo sobre a cultivar mais tolerante, BRS Bojurú.

Tabela 1. Emergência de plântulas em casa de vegetação (E\%) e índice de velocidade de emergência (IVE) de plântulas de duas cultivares de arroz, BRS Querência (BRS-Q) e BRS Bojurú (BRS-B), tratadas com NaCl (100 mM) $+\operatorname{EBR} 1(0,01 \mu \mathrm{M}), \operatorname{EBR} 2(0,1 \mu \mathrm{M})$ e EBR3 $(1,0 \mu \mathrm{M})$.

\begin{tabular}{ccccc}
\hline & \multicolumn{2}{c}{$\mathrm{E}(\%)$} & \multicolumn{2}{c}{ IVE } \\
\cline { 2 - 5 } Tratamentos & BRS-Q & BRS-B & $10,21 \mathrm{~B}$ & BRS-B \\
\hline Controle & $87 \mathrm{BC}$ & $84 \mathrm{~A}$ & $8,6 \mathrm{C}$ & $8,34 \mathrm{~B}$ \\
$\mathrm{NaCl}(100 \mathrm{mM})$ & $82 \mathrm{C}$ & $83 \mathrm{~A}$ & $10,95 \mathrm{~B}$ & $8,81 \mathrm{~B}$ \\
$\mathrm{NaCl}+\mathrm{EBR} 1$ & $89 \mathrm{AB}$ & $83 \mathrm{~A}$ & $10,35 \mathrm{~B}$ & $8,17 \mathrm{~B}$ \\
$\mathrm{NaCl}+\mathrm{EBR} 2$ & $89 \mathrm{AB}$ & $82 \mathrm{~A}$ & $11,9 \mathrm{~A}$ & $6,65 \mathrm{C}$ \\
$\mathrm{NaCl}+\mathrm{EBR} 3$ & $93 \mathrm{~A}$ & $79 \mathrm{~B}$ & 6,21 & 6,85 \\
\hline $\mathrm{CV} \%$ & 2,43 & 3,27 &
\end{tabular}

Médias seguidas pela mesma letra maiúscula na coluna (concentração de 24-EBR) não diferem a nível de significância de 5\% pelo Teste de Tukey.

Fonte: Elaboração dos autores.

Resultados semelhantes aos encontrados neste trabalho, com a cultivar BRS-Querência, foram descritos por Anuradha e Rao (2001), que evidenciaram redução considerável no efeito inibitório da salinidade sobre a emergência de sementes de arroz, quando a solução salina foi suplementada com 24-epibrassinolídeo. Da mesma forma, o aumento significativo no percentual de germinação em Raphanus sativus L. (ANURADHA; RAO, 2007) e Brassica juncea (L.) Czern sob estresse por cádmio, em trigo por altas temperaturas e sob estresse hídrico (VARDHINI; RAO, 2003) é atribuído a aplicação do 24-epibrassinolídeo.

Os efeitos da salinidade podem estar relacionados tanto ao fator osmótico do sal, limitando a hidratação das sementes, quanto ao efeito tóxico do sal sobre o embrião e às células da membrana do endosperma (LIMA et al., 2004). Ainda pode ser atribuída à restrição imposta à divisão e ao alongamento celular, bem como, a mobilização das reservas indispensáveis a ocorrência do processo germinativo (BAJGUZ; HAYAT, 2009).

O comprimento do sistema radicular das plântulas das duas cultivares de arroz foi reduzido pela salinidade e restabelecido pela aplicação do 24-epibrassinolídeo. No entanto, apenas na cv BRS Querência, as duas concentrações mais elevadas do regulador de crescimento foram capazes de induzir um aumento no comprimento das raízes (Tabela 2).

O comprimento da parte aérea das plântulas da cv. BRS Querência foi reduzido pela salinidade e restabelecido pela aplicação do 24-epibrassinolídeo na menor concentração $(0,01 \mu \mathrm{M})$, sendo incrementado pela suplementação da solução salina com as concentrações mais elevadas $(0,1$ e $1,0 \mu \mathrm{M})$ (Tabela 2). No entanto, o alongamento 
da parte aérea na cv. BRS Bojurú não foi alterado pela salinidade ou adição do 24-epibrassinolídeo na menor concentração $(0,01 \mu \mathrm{M})$, porém, as concentrações mais elevadas do regulador de crescimento reduziram o comprimento da parte aérea, comparado às plântulas do controle (Tabela2).

Estes resultados sugerem que o 24-epibrassinolídeo induz o crescimento da parte aérea em cultivares suscetíveis a salinidade e reduz em cultivares tolerantes.

Tabela 2. Comprimento da raiz (CR) e da parte aérea (CPA)de plântulas de duas cultivares de arroz, BRS Querência (BRS-Q) e BRS Bojurú (BRS-B), tratadas com NaCl (100 mM) + EBR1 $(0,01 \mu \mathrm{M}), \operatorname{EBR} 2(0,1 \mu \mathrm{M})$ e EBR3 $(1,0 \mu \mathrm{M})$

\begin{tabular}{ccccc}
\hline & \multicolumn{2}{c}{$\mathrm{CR}\left(\mathrm{mm} \mathrm{plântula}^{-1}\right)$} & \multicolumn{2}{c}{ CPA $\left(\mathrm{mm}\right.$ plântula $\left.{ }^{-1}\right)$} \\
\cline { 2 - 5 } Tratamentos & BRS-Q & BRS-B & BRS-Q & BRS-B \\
\hline Controle & $153,1 \mathrm{~B}$ & $114,1 \mathrm{~A}$ & $165,0 \mathrm{~B}$ & $173,2 \mathrm{~A}$ \\
$\mathrm{NaCl}(100 \mathrm{mM})$ & $124,4 \mathrm{C}$ & $98,2 \mathrm{~B}$ & $146,1 \mathrm{C}$ & $167,5 \mathrm{~A}$ \\
$\mathrm{NaCl}+\mathrm{EBR} 1$ & $159,3 \mathrm{~B}$ & $111,4 \mathrm{~A}$ & $159,2 \mathrm{~B}$ & $172,5 \mathrm{~A}$ \\
$\mathrm{NaCl}+\mathrm{EBR} 2$ & $173,2 \mathrm{~A}$ & $118,4 \mathrm{~A}$ & $172,3 \mathrm{~A}$ & $134,8 \mathrm{~B}$ \\
$\mathrm{NaCl}+\mathrm{EBR} 3$ & $199,1 \mathrm{~A}$ & $106,5 \mathrm{~A}$ & $173,1 \mathrm{~A}$ & $129,6 \mathrm{~B}$ \\
\hline $\mathrm{CV} \%$ & 3,25 & 3,63 & 2,86 & 2,25 \\
\hline
\end{tabular}

Fonte: Elaboração dos autores.

Uma das explicações mais aceitas para a inibição do crescimento pelo sal é o desvio de energia do crescimento para a manutenção, sendo que a diminuição da massa seca pode refletir o custo metabólico de energia, associado à adaptação a salinidade e redução do ganho de carbono (RICHARDSON; MCCREE, 1985). Pode ser incluída nestes processos a regulação do transporte e distribuição iônica em vários órgãos e dentro das células, como a síntese de solutos orgânicos para osmorregulação e a manutenção da integridade das membranas celulares. Assim a menor redução no crescimento no genótipo tolerante ocasionada pela salinidade (Tabela 2) pode estar associada ao menor custo energético para osmorregulação, conseguido por meio da acumulação e da compartimentalização de solutos inorgânicos no vacúolo e solutos orgânicos no citoplasma.
O acúmulo de massa seca nas raízes das plântulas da cv. BRS Querência foi reduzido pela salinidade e incrementando em função do aumento da concentração de 24-epibrassinolídeo utilizada (Tabela 3). Na BRS Bojurú, entretanto, a massa seca foi restabelecida dos danos causados pela presença do $\mathrm{NaCl} 100 \mathrm{mM}$ na menor concentração de 24-epibrassinolídeo $(0,01 \mu \mathrm{M})$ sendo que, nas concentrações mais elevadas ocorreram reduções nos valores desta variável (Tabela 3). É importante ressaltar que estas cultivares, nas condições de laboratório, não apresentaram restabelecimento das massas fresca e seca pela aplicação do 24-epibrassinolídeo após o decréscimo induzido pela salinidade (LARRÉ; MORAES; LOPES, 2011) enquanto que em casa de vegetação, a cultivar mais sensível (BRS Querência) teve sua condição inicial restabelecida pela aplicação da menor concentração de 24-epibrassinolídeo (0,01 $\mu \mathrm{M})$. 
Tabela 3. Massa de Matéria seca da raiz (MSR) e da parte aérea (MSPA) de plântulas de duas cultivaresde arroz, BRS Querência (BRS-Q) e BRS Bojurú (BRS-B), tratadas com NaCl $(100 \mathrm{mM})+\operatorname{EBR} 1(0,01 \mu \mathrm{M})$, EBR2 $(0,1 \mu \mathrm{M})$ e EBR3 $(1,0 \mu \mathrm{M})$.

\begin{tabular}{ccccc}
\hline & \multicolumn{2}{c}{ MSR $\left(\mathrm{mg} \mathrm{plântula}^{-1}\right)$} & \multicolumn{2}{c}{ MSPA $\left(\mathrm{mg}\right.$ plântula $\left.{ }^{-1}\right)$} \\
\cline { 2 - 5 } Tratamentos & BRS-Q & BRS-B & BRS-Q & BRS-B \\
\hline Controle & $118 \mathrm{C}$ & $110 \mathrm{~A}$ & $251 \mathrm{~B}$ & $233 \mathrm{~A}$ \\
$\mathrm{NaCl}(100 \mathrm{mM})$ & $96 \mathrm{D}$ & $84 \mathrm{~B}$ & $207 \mathrm{C}$ & $219 \mathrm{~A}$ \\
$\mathrm{NaCl}+\mathrm{EBR} 1$ & $139 \mathrm{~B}$ & $88 \mathrm{~B}$ & $258 \mathrm{~B}$ & $221 \mathrm{~A}$ \\
$\mathrm{NaCl}+\mathrm{EBR} 2$ & $159 \mathrm{~B}$ & $74 \mathrm{C}$ & $278 \mathrm{~A}$ & $184 \mathrm{~B}$ \\
$\mathrm{NaCl}+\mathrm{EBR} 3$ & $211 \mathrm{~A}$ & $74 \mathrm{C}$ & $270 \mathrm{~A}$ & $181 \mathrm{~B}$ \\
\hline $\mathrm{CV} \%$ & 3,24 & 2,98 & 3,04 & 2,81 \\
\hline
\end{tabular}

Fonte: Elaboração dos autores.

O acúmulo de massa seca na parte aérea foi alterado pela aplicação do 24-epibrassinolídeo, nas duas cultivares. A cv. BRS Querência apresentou decréscimo nos valores de massa seca na parte aérea em função da salinidade quando comparado ao controle (Tabela 3), mas foi restabelecido pela aplicação do 24-epibrassinolídeo na menor concentração $(0,01 \mu \mathrm{M})$ e, incrementado pela adição de concentrações mais elevadas $(0,1$ e 1,0 $\mu \mathrm{M})$. Entretanto, na cv. BRS Bojurú a salinidade não reduziu a massa seca acumulada na parte aérea, somente houve diminuição desta variável ocasionada pela aplicação do 24-epibrassinolídeo em concentrações mais elevadas $(0,1$ e $1,0 \mu \mathrm{M})$ (Tabela 3).

A cultivar BRS Querência apresentou redução na área foliar pela salinidade e assim se manteve com a aplicação do 24-epibrassinolídeo na concentração mais baixa, $(0,01 \mu \mathrm{M})$, todavia nas concentrações mais elevadas do regulador de crescimento $(0,1 \mathrm{e}$ $1,0 \mu \mathrm{M})$ a área foliar foi restabelecida (Tabela 4). A cultivar BRS Bojurú não apresentou alteração na área foliar quando exposta a salinidade, somente teve a área foliar reduzida, em relação ao controle, quando o tratamento salino foi suplementado pelo 24-epibrassinolídeo nas concentrações maiores que $0,01 \mu \mathrm{M}$.A área foliar é uma característica de crescimento importante, pois mostra o tamanho do aparato fotossintético, que determina o acúmulo de massa seca, o metabolismo vegetal, a capacidade fotossintética potencial, o rendimento e a qualidade de colheita (SEVERINO et al., 2004; NASCIMENTO, 2009).

As duas cultivares apresentaram comportamento diferenciado no que concerne ao conteúdo de clorofila. A cv. BRS Querência apresentou decréscimo na concentração de clorofila total quando exposta ao $\mathrm{NaCl} 100 \mathrm{mM}$, porém a condição inicial (controle) foi restabelecida quando a solução salina foi suplementada pelo 24-epibrassinolídeo na concentração mais baixa e, as concentrações mais elevadas do 24-epibrassinolídeo, 0,1 e 1,0 $\mu \mathrm{M}$, foram capazes de incrementar o conteúdo de clorofila a níveis superiores ao inicial. No entanto, a cv. BRS Bojurú não teve o conteúdo de clorofila alterado pela salinidade ou aplicação do regulador de crescimento (Tabela 4). Conforme descrito por Lima et al. (2004), a presença de sal não altera a síntese de clorofila nas cultivares mais tolerantes. Em folhas de trigo ocorre aumento no conteúdo de clorofila atribuído a alta concentração $(10 \mu \mathrm{M})$ de 24-epibrassinolídeo utilizada (SAĞLAM-ÇAĞ, 2007). 
Tabela 4. Área foliar (AF) e concentração de clorofila total (CClt), de plântulas de duas cultivares de arroz, BRS Querência (BRS-Q) e BRS Bojurú (BRS-B), tratadas com NaCl $(100 \mathrm{mM})+$ EBR1 $(0,01 \mu \mathrm{M})$, EBR2 $(0,1 \mu \mathrm{M})$ e EBR3 $(1,0 \mu \mathrm{M})$.

\begin{tabular}{ccccc}
\hline \multirow{2}{*}{ Tratamentos } & \multicolumn{2}{c}{$\mathrm{AF}\left(\mathrm{mm}^{2}\right.$ plântula $\left.^{-1}\right)$} & \multicolumn{2}{c}{$\mathrm{CCl}_{+}\left(\mathrm{mg} \mathrm{g}^{-1} \mathrm{MF}\right)$} \\
\cline { 2 - 5 } & $\mathrm{BRS}-\mathrm{Q}$ & BRS-B & BRS-Q & BRS-B \\
\hline Controle & $35,5 \mathrm{~A}$ & $26,9 \mathrm{~A}$ & $1,18 \mathrm{~B}$ & $1,33 \mathrm{~A}$ \\
$\mathrm{NaCl}(100 \mathrm{mM})$ & $26,8 \mathrm{~B}$ & $23,5 \mathrm{~A}$ & $0,88 \mathrm{C}$ & $1,28 \mathrm{~A}$ \\
$\mathrm{NaCl}+\mathrm{EBR} 1$ & $27,1 \mathrm{~B}$ & $23,6 \mathrm{~A}$ & $1,12 \mathrm{~B}$ & $1,30 \mathrm{~A}$ \\
$\mathrm{NaCl}+\mathrm{EBR} 2$ & $34,7 \mathrm{~A}$ & $18,5 \mathrm{~B}$ & $1,33 \mathrm{~A}$ & $1,27 \mathrm{~A}$ \\
$\mathrm{NaCl}+\mathrm{EBR} 3$ & $36,2 \mathrm{~A}$ & $16,9 \mathrm{~B}$ & $1,31 \mathrm{~A}$ & 4,84 \\
\hline $\mathrm{CV} \%$ & 1,81 & 2,12 & 3,96 & \\
\hline
\end{tabular}

Médias seguidas pela mesma letra maiúscula na coluna (concentração de 24-EBR) não diferem à nível de significância de 5\% pelo Teste de Tukey.

Fonte: Elaboração dos autores.

A concentração de clorofila (Tabela 4) assim como o acúmulo de massa seca da parte aérea (Tabela 3) são condizentes, sugerindo que o 24-epibrassinolídeo está envolvido na aceleração da síntese de clorofila em cultivares mais suscetíveis ao sal, possibilitando, desta forma, um ajuste da atividade fotossintética em condições adversas, favorecendo o incremento de biomassa na parte aérea.

A promoção do crescimento é associada à elevação dos níveis de clorofila, imposta pela adição de24-epibrassinolídeo (ANURADHA; RAO, 2003), sugerindo que os resultados apresentados na Tabela 2 , referentes ao comprimento de parte aérea, estejam vinculados, diretamente, ao incremento da síntese de clorofila induzido pelo 24-epibrassinolídeo na cv. BRS Querência, na presença de sal.

A aplicação do brassinosteróide normalmente proporciona resposta positiva no crescimento das plântulas por estar envolvido na modificação da estrutura e permeabilidade das membranas em situação de estresse promovendo a atividade do sistema de defesa antioxidante, além de ativar a bomba de prótons, estimular a síntese de proteínas e ácidos nucléicos (BAJGUZ, 2000) e regular a expressão gênica (FELNER, 2003), estimular a atividade enzimática (ANURADHA; RAO, 2001) e o aproveitamento fotossintético. O efeito cumulativo da modificação de todos estes processos incrementa o crescimento da plântula, principalmente em condição de estresse.

A aplicação de 24-epibrassinolídeo incrementou o crescimento e induziu a síntese de clorofila em plântulas de Vigna radiata L. Wilczek, sob estresse por alumínio (ABDULLAHI et al., 2003; ALI et al., 2008). Da mesma forma, o 24-epibrassinolídeo também é reconhecido por restabelecer ou induzir a germinação e todas as características de crescimento em trigo e sorgo sob estresse hídrico (VARDHINI; RAO, 2003), além de aumentar a tolerância das plântulas sob estresse por metais pesados como, cádmio em Brassica juncea L. Czern. (HAYAT et al., 2007) e Raphanus sativus L. (ANURADHA; RAO, 2007) e alumínio em Vigna radiata L. Wilczek (ALI et al., 2008).

A salinidade reduz o crescimento e muitos processos fisiológicos como consequência de alterações metabólicas induzidas pelo sal. Aliado a isso, os resultados obtidos pela aplicação do 24-epibrassinolídeo estão relacionados com a regulação da atividade do sistema enzimático antioxidante, alteração nos níveis de ácidos nucléicos, proteínas solúveis e prolina livre em resposta a condição de estresse (ANURADHA; RAO, 2001). 


\section{Conclusão}

O 24-epibrassinolídeo, na cv. BRS Querência induz aumento em todas as características de crescimento.

Os efeitos deletérios da salinidade são minimizados pelo 24-epibrassinolídeo, na cultivar sensível a salinidade.

$\mathrm{Na}$ cv. BRS Bojurú, as maiores concentrações reduzem as características de crescimento, não alterando a concentração de clorofila total.

\section{Referências}

ABDULLAHI, B. A.; GU, X.; GAN, Q.; YANG, Y. Brassinolide amelioration of aluminium toxicity in mung bean seedling growth.Journal of Plant Nutrition, New York, v. 26, n. 9, p. 1725-1734, 2003.

AGRIANUAL. Anuário estatístico da agricultura brasileira. São Paulo: FNP, 2012. p. 165-176.

ALI, B.; HASAN, S. A.; HAYAT, S.; HAYAT, Q.; YADAV, S.; FARIDUDDIN, Q.; AHMAD, A. A role for brassinosteroids in the amelioration of aluminium stress through antioxidant system in mung bean (Vignaradiata L. Wilczek). Environmental and Experimental Botany, Elmsford, New York, v. 62, n. 2 p. 153-159, 2008.

ALSHAMMARY, S. F.; QIAN, Y. L.; WALLNER, S. J. Growth response of four turfgrass species to salinity. Agricultural Water Management, Amsterdam, v. 66, n. 1, p. 97-101, 2004.

ANURADHA, S.; RAO, S. S. R. Aplication of brassinosteroids to rice seeds (Oryza sativa $\mathrm{L}$.) reduced the impact of salt stress on growth, prevented photosynthetic pigment loss and increased nitrate reductase activity. Plant Growth Regulation, Dordrecht, Holanda, v. 40, n. 1, p. 29-32, 2003.

Effect of brassinosteroids on salinity stress induced inhibition of seed germination and seedling growth of rice (Oryza sativa L.). Plant Growth Regulation,Dordrecht, Holanda,v. 33, n. 2, p. 151-153, 2001.

R. The effect of brassinosteroids on radish (Raphanussativus L.) seedlings growing under cadmium stress.Plant Soil Environment, The Hague, v. 53. n. 11, p. 465-472, 2007.
ARNON, D. I. Copper enzymes in isolated chloroplasts. Polyphenol oxidase in Beta vulgaris.Plant Physiology, Washington, v. 24, n. 1, p. 1-15, 1949.

BAJGUZ, A. Effect of brassinosteroids on nucleic acid and protein content in cultured cells of Chlorella vulgaris. Plant Physiology and Biochemistry, New Delhi, v. 38, n. 3, p. 209-215, 2000.

BAJGUZ, A.; HAYAT, S. Effects of brassinosteroids on the plant responses to environmental stresses. Plant Physiology and Biochemistry, New Delhi, v. 47, n. 1, p. $1-8,2009$.

BRASIL. Ministério da Agricultura, Pecuária e Abastecimento. Secretaria de Defesa Agropecuária. Regras para análise de sementes. Brasília, DF: Mapa/ ACS, 2009. 395 p.

FELNER, M. Recentprogress in brassinosteroidsresearch: hormoneperceptionandsignaltransduction. In: HAYAT, S.; HAMAD, A. (Ed.). Brassinosteroids: bioactivity and crop productivity. Dordrecht: Kluwer Academic Publishe, 2003. cap. 3, p. 69-86.

HAYAT, S.; ALI, B.; AHMAD, A. Response of Brassica juncea to 28-homobrassinolide grown from the seeds exposed to salt stress. Journal of PlantBiology, Amsterdam, v. 33, n. 1, p. 169-174, 2006.

LARRÉ, C. F.; MORAES, D. M.; LOPES, N. F. Qualidade fisiológica de sementes de arroz tratadas com solução salina e 24-epibrassinolídeo. Revista Brasileira de Sementes, Londrina, v. 33, n. 1, p. 86-94, 2011.

LICHTENTHALER, H. K. Clorophylls and carotenoids: pigments of photosynthetic biomembranes. Methods in Enzimology, New York, v. 148, n. 34, p. 333-382, 1987.

LIMA, M. G. S.; LOPES, N. F.; BACARIN, M. A.; MENDES, C. R. Efeito do estresse salino sobre a concentração de pigmentos e prolina em folhas de arroz. Bragantia, Campinas, v. 63, n. 3, p. 335-340, 2004.

MAGUIRRE, J. D. Speed of germination aid in selection and evaluation for seedling and vigor. Crop Science, Madison, v. 2, n. 2, p. 176-177, 1962.

MANSOUR, M. M. F.; SALAMA, K. H. A. Cellular basis of salinity tolerance in plants.Environmental and Experimental Botany, Elmsford, v. 52, n. 2, p. 113-122, 2004.

MUNNS, R. Comparative physiology of salt and water stress. Plant, Cell \& Environment, Austrália, v. 25, n. 2, p. 239-250, 2002. 
NASCIMENTO, S. P. do. Efeito do déficit hídrico em feijão-caupi para identificação de genótipos com tolerância à seca. 2009. Dissertação (Mestrado em Agronomia -Produção Vegetal) - Universidade Federal do Piauí, Piauí.

RAO, S. S. R.; VARDHINI, B. V. V.; SUJATHA, E.; ANURADHA S. Brassinosteroids - a new class of phytormones. Current Science, Bangalore, v. 82, n. 10, p. 1239-1245, 2002.

RICHARDSON, S. G.; McCREE, K. J. Carbon balance and water relations of sorghum exposed to salt and water stress. Plant Physiology, Washington, v. 79, n. 11, p. 1015-1020, 1985.

SAĞLAM-ÇAĞ, S. The effect of epibrassinolide on senescence in wheat leaves. Biotechnology \& Biotechnology, Frankfurt, v. 21, n. 1, p. 63-65, 2007.

SANTOS, C.; AZEVEDO, H.; CALDEIRA, G. In situ and in vitro senescence induced by $\mathrm{KCl}$ stress: nutritional imbalance, lipid peroxidation and antioxidant metabolism. Journal of Experimental Botany, Lancaster, v. 52, n. 355, p. 351-360, 2001.
SASSE, J. M. Physiological actions of brassinosteroids: on update. Journal of Plant Growth Regulation, New York, v. 22, n. 4, p. 276-288, 2003.

SEVERINO, L. S.; CARDOSO, G. D.; VALE, L. S. do; SATOS, J. W. dos. Método para determinação da área foliar da mamoneira. Revista Brasileira de Oleaginosas e Fibrosas, Campina Grande, v. 8, n. 1, p. 753-762, 2004.

SHARMA, P.; BHARDWAJ, R.; ARORA, N.; ARORA, H. K. Effect of 28-homobrassinolide on growth, zinc metal uptake and antioxidative enzyme activities in Brassica juncea L. seedlings. Brazilian Journal Plant Physiology, Rio de Janeiro, v. 19, n. 3, p. 203-207, 20007.

VARDHINI, B. V.; RAO, S. S. R. Amelioration of osmotic stress by brassinosteroids on seed germination and seedling growth of three varieties of sorghum. Plant Growth Regulation, Dordrecht, v. 41, n. 1, p. 25-31, 2003.

VIEIRA, R. D. ; CARVALHO, N. M. Testes de vigor em sementes. Jaboticabal: FUNEP, 1994. 164 p.

ZULLO, M. T.; ADAM, G. Brassinosteroid phytormones - structure, bioactivity and applications. Brazilian Journal of Plant Physiology, Rio de Janeiro, v. 14, n. 3, p. 143-181, 2002. 
